\title{
EDITORIAL
}

\section{MORAL Y PRECIOS}

Durante los primeros meses del año hemos podido asistir a una activa campaña de prensa, radio, etc., en pro del abaratamiento de los precios. Su origen, la ley de reforma de las $\mathrm{Ha}$ ciendas Municipales. En esta ley se prevé la supresión de los arbitrios de los municipios sobre los artículos de consumo, y era, por lo mismo, lógico y justo esperar un descenso de los precios en un volumen aproximadamente igual al montante global de los impuestos suprimidos.

La campaña ha querido ser, sobre todo, una presión moral sobre el comercio en nombre de la desarticulada, amorfa, sufrida gran masa de consumidores. Tal vez se ha prometido y esperado demasiado el consumidor anónimo: tomada en bloque es muy considerable la cifra de 3.700 millones de pesetas en impuestos desaparecidos, que ante él ha aireado la prensa diaria.

¿Por qué no habría de esperar en justicia una baja espectacular de los precios? Con medias verdades se ha creado en él esta impresión, que es lo que se pretendía, pero que no responde exactamente a la realidad del mercado, puesto que la desgravación significa la suma nada exorbitante de 0,35 pesetas por español y día. De todas maneras es de justicia que los impuestos suprimidos no pasen del presupuesto de los ayuntamientos a la cuenta de resultados de los comerciantes particulares, sino al activo de las economias familiares. Además, en determinados consumos, los porcentajes de desgravación no son nada despreciables: en Madrid, v. gr., el 23 por 100 en cafés, bares, cafeterías; el 22 por 100 en las salas de cine, etc. 
Pero creemos que la campaña ha puesto de manifiesto una realidad más importante todavia: la realidad del consumidor desvalido, esquivo, difícil, como un perro suelto y perdido, a merced de los intereses profesionales de una red comercial distribuidora tal vez demasiado enmarañada, un tanto turbia, tal vez multitudinaria en demasía. Por esta vez los medios de información le dieron su apoyo (al consumidor), y este apoyo ha encontrado un eco enorme en la opinión.

Creemos que en esta situación actual del comercio interior se corre gravemente el riesgo de que el sistema de precios se aparte notablemente de las normas de la justicia por el doble fenómeno que hemos apuntado: la desorganización institucional de los consumidores, y las rentas moralmente poco claras que se originan en algunos eslabones de la cadena nacional de intermediarios.

Asociaciones de consumidores existen en numerosos paises. En este mismo numero de FOMENTO podrá ver el lector una breve referencia al último congreso internacional de estas asociaciones, celebrado recientemente en Bruselas. Son de un vivo interés comunitario; por estas razones, entre otras: $1 .{ }^{\text {" garanti- }}$ zan la calidad de los productos, puesto que los boletines informativos de la asociación dan noticia regular e implacablemente sobre las cualidades reales de cada uno de los artículos, evitando así a la larga, en gran medida, las posibles manipulaciones desleales de productores y comerciantes. 2. ${ }^{\circ}$ Mediante sus medios informativos contribuyen en buen grado a la transparencia del mercado, en precios y calidades, $y$, por lo mismo, a la competencia entre los diversos bienes de consumo, con su posible repercusión favorable en el nivel de precios. $3 .^{\circ}$ Defienden los intereses del consumidor contra los métodos "cientificos" de publicidad desorbitada, y son, además, hoy, un contrapeso cada vez más necesario para el equilibrio de fuerzas dentro de nuestro sistema económico-social. Tan necesario - podrá pensar alguno- en nuestros días, como el clásico equilibrio profesional: sindicatos obreros-organizaciones patronales.

La iniciativa privada y la política comercial podrán actuar sin duda, eficazmente en este sentido. 
Por nuestra parte deseamos que una inflación desencadenada no haga inútil el grave sacrificio impuesto a los españoles durante los dos años de la estabilización económica. fuzgamos que este sacrificio justifica en primer lugar la adopción de severas medidas contra las alzas fraudulentas de los precios. Pero creemos que la acción se ha de orientar sobre todo hacia una clarificación e institucionalización del mercado interior, en el sentido indicado; con lo que no hacemos sino aportar nuestro grano de arena a lo que tan ampliamente se ha reflejado en la opinión pública en este primer trimestre de 1963. 